\title{
The Occupational Diseases and Countermeasures of Pianists
}

\author{
Ying Wang \\ Department of Film and Television Arts, Shanghai Publishing and Printing College, Shanghai, China \\ Email:66929155@qq.com
}

How to cite this paper: Wang, Y. (2019) The Occupational Diseases and Countermeasures of Pianists. Health, 11, 1147-1151 https://doi.org/10.4236/health.2019.119088

Received: August 31, 2019

Accepted: September 21, 2019

Published: September 24, 2019

Copyright $\odot 2019$ by author(s) and Scientific Research Publishing Inc. This work is licensed under the Creative Commons Attribution International License (CC BY 4.0).

http://creativecommons.org/licenses/by/4.0/

\begin{abstract}
Piano performance is a combination of physical and mental exercise. If there is no correct playing habit or good playing method, it is easy to lead to diseases which are called occupational diseases medically. These occupational diseases will directly affect the pianists' performance state or even make them unable to play. This paper analyses the causes of tenosynovitis, ligament strain, thumb disease, neuromuscular pain and shoulder neuritis or neuralgia, and explains the methods of reducing or eliminating the diseases combining with cases, in the hope of giving some help to piano-playing patients with their occupational diseases.
\end{abstract}

\section{Keywords}

Piano, Occupational Disease, Performance, Muscle, Tendon Sheath

\section{Introduction}

With the increasing popularity of piano in China, along with the satisfaction and joy, it brings troubles and pains to those who practice playing the piano. It's very common to see many pianists suffer from tenosynovitis, myositis, muscular atrophy, thumb disease, neuromuscular disease and so on. According to a survey of 3000 instrumentalists in 40 bands conducted by a German institute of surgery, more than two-thirds of professional instrumentalists are prone to have chiropractic diseases, while the proportion of people engaged in other professions is less than a half. A recent study of 1353 instrumentalists by the Cleveland clinic foundation found that $64 \%$ had various skeletal muscle diseases, $20 \%$ had peripheral neuropathy, and $8 \%$ had localized dystonia. These figures show that almost 80 percent of music performers suffer from diseases brought about by the profession. These diseases are usually the result of violating the natural physiological law of muscle work, so music performers should pay attention to this 
problem [1] [2].

The piano, like a competitive sport, is a highly technical instrument. It can only be mastered with a lot of hard practice. However, if the playing position is not correct or the playing method is wrong during the practice, the coordination of different parts of the organ may be damaged, and some muscles are forced to perform the work beyond their capacity. This usually makes the ligaments, muscles and tendons between the fingers too tight, which will lead to some diseases such as tenosynovitis, tendonitis and other complications. The following are some common occupational diseases of pianists:

\section{Tenosynovitis}

Tenosynovitis is a common disease among pianists. Due to incorrect chord playing, octaves, or wide spans, the muscles between the bones are not actively involved when the fingers are stretched. In this case, the forearms are stretched too tight, and the muscles are overstretched, thus contributing to the occurrence of the disease. The wrist is a high-incidence area of tenosynovitis. The wrists need to be moved frequently during the performance. Playing the musical phrases with a series of wrist movements well requires excessive muscle movement, which will probably result in the hurt of wrists. The same case will also happen while playing the span of an octave or over octave, because the coordination of the muscles of the arm and wrist is not timely. Repeated excessive friction between the tendon sheath and tendon will cause globular swelling on the wrist. Patients feel sore in the wrist so that they will make a small friction sound when playing the piano. If the illness is serious, it is difficult for the pianists to continue to play.

\section{Ligament Injury}

Ligament injuries are common if you don't practice properly. Ligament damage can be caused by the following different reasons: there is no support from the underlying muscle tissue or no support for the fingers on the piano keyboard, which will cause wrong using of the finger muscles and muscle ligament to tear; arms are "hung up"-when playing, the muscles are too tense and the arms are too stiff; the muscles of the upper arm are overtired, causing injury; the bending fingers are raised too high, straining the ligaments between the hand muscles; and lacking the necessary cooperation of palm muscles during playing. These wrong playing methods are the culprit and initiator of ligament injury.

\section{Thumb Disease}

The thumb, the strongest of the five fingers, is the hinge that connects notes. Improper use of thumb when playing pianos may also bring bad consequences, such as strong stretch; squeezing or fixing the thumb tensely; no enough resting in the palm while bending and holding the thumb too tightly. All these can cause pain and discomfort in the thumb. In severe cases, the muscles of the palm are 
like hills and may atrophy if left untreated.

\section{Neuromuscular Pain}

Neuromuscular pain occurs with muscular diseases and tendinopathy. This is the result of chronic neuromuscular tension, which happens more likely in the torso and limbs due to long-term forced posture and the static tension in certain muscle group. It mainly involves the proximal muscles of the upper arms and hands. That is, excessive lifting of the phalanx when the hands are tied or too slow movement of the elbows and excessive tightening of the shoulders (humeri) when playing. The symptom is pain in the most-burdened muscles during performance, and often accompanied by vascular neuralgia. The pain worsens at night, and the patient feels sluggish and weak [3]. Additionally, occupational spasm, also known as occupational neurosis, is another common occupational disease of music performers. During the performance of musical instruments, fingers spasm happens, with its muscle and tendon sheath changing [4]. Symptom of this kind of disease can commonly disappear after stopping playing for a period of time, but it often relapses.

\section{Shoulder Neuritis or Neuralgia}

This is due to the lifting of the shoulder strap, collarbone and humerus while playing, or the unnatural drooping of the elbow and humerus while playing chords and octaves.

In addition to the above reasons, muscular neuropathy, tenosynovitis and tendonitis may occur when muscle vitality suddenly weakens and muscle fatigue suddenly increases. All the unreasonable playing ways that may lead to occupational diseases encountered in practice cannot be listed here one by one.

When I was studying in St. Petersburg, due to tenosynovitis, I also learned some methods to reduce inflammation while being treated in hospital. I specially consulted the doctor in the conservatory of music who specialized in treating this disease and obtained some successful cases. So how do we deal with these situations?

In these cases, special training can be provided to eliminate neurological work habits and other inconveniences associated with occupational diseases. In addition, it can free the pianists and help them regain the ability to master the piano, so that the pianists' personality began to emerge unexpectedly. These exercises should be carried out in a certain order and amount. We should treat each specific case separately, because each student plays differently and makes different mistakes, and each student gets sick in different forms. Here are two examples:

Student A-Anton. During the first year of the course, he often felt uncomfortable to play. His elbows were tight and shoulders not relaxed; fingers were restricted in many movements. When playing lyric works, the melody changed soft, his playing posture was not too tight, and his tense muscle began to relax. When the melody reached to a fast rhythm, there would be tension which is due 
to insufficient exercise of fingers. He did not clearly understand his teacher's tutoring methods while imitating and his fingers did not coordinate well with each other. These coaching techniques are designed to stretch the arms and hands, but can cause discomfort in the shoulder joints and lead to weight bearing on the arms. After a year, he felt his arm tighten at times but did not notice it because he had long been used to the discomfort of playing. As the complexity of the repertoire and the difficulty of playing fingering have gradually increased, the methods to solve new artistic and technical problems have been insufficient. Large-scale repertoire and high excitement before appearing on the stage cause physiological over-tension, which makes disease develop in arms (wrist joints and forearms inside). It starts in left arm and then in right arm. When Student A arrived at the occupational disease institute, he had already been diagnosed with tenosynovitis and tendonitis [5].

During the course of treatment, Student A started with gymnastics training to develop the organization of fingers and correct muscle movements, and then began to practise on the piano. He developed the ability to control his feelings while practicing. Gradually, he learned how to cultivate his own comfortable playing state and he adjusted the power of pressing the keys. And then he mastered persistence. In this way, he could finish large-scale and complicated repertoire in the conservatory and participate in the international piano competition.

Student B-Natasha. Natasha often felt pain in wrist when playing the piano and her body was particularly tired. It was, in her words, like a weight hanging on her wrist. This often happens when playing high notes and fast rhythms. She was diagnosed in the initial phase. An experienced teacher pointed out several improper finger-using behaviors that lead to her illness: the tired fingers have been unable to support on the keyboard, so the sound played is lack of emotion and very superficial; most of the arm doesn't participate in playing; her body is bent too much while playing. The first thing you need to do is to get your palms and shoulders moving, which involves doing exercises, practicing the support points and doing stretches, "Flying" exercises, alternating between high and low pitches, and jumping (strong and weak) on each finger. After correcting the sitting posture, Student B was able to straighten her wrists and no longer felt pressure in her wrists. She tried to transfer the power of piano playing from her back to her arms, then to her wrists, finally to her fingertips. It was like turning on a tap. Power flew from the back and shoulders to the fingertips. She felt that the whole arm could work as one. With this exercise, she no longer felt discomfort in her wrist. She has felt much better after two months of treatment.

In general, occupational diseases are caused by the imitation of the surface forms of playing, which leads to the non-standard performance without correct rules. The lack of listening to the effect of sound, namely, the unconscious playing and the pursuit of fast playing eventually led to the emergence of disease. How do we respond when we suffer from these diseases? First, the relatively healthy arm needs to be corrected first. Change the way it plays. Next, practice 
the more painful arm. This will make the painful arm more comfortable and convenient. This way of playing will gradually reduce the pain until it disappears, and will also promote the relative comfort of the other arm, thus reducing the symptoms. However, the duration of treatment usually depends on the nature of the disease and the degree of illness, which is mainly determined by the patients' disease characteristics, endurance and their own determination and fitness to training. People who experience pain are always better able to assess it than those who teach them [6]. Of course, there may be rebound symptoms, but with right playing, the player can eliminate them. These trainings should be carried out in a certain order and amount, and treated separately according to each specific situation, because each student plays differently and makes different mistakes, and each student gets sick in different forms. Furthermore, these treatments (correcting abnormal habits and incorrect playing methods) must be done after the phenomenon of disease has been eliminated by medical means.

\section{Conflicts of Interest}

The author declares no conflicts of interest regarding the publication of this paper.

\section{References}

[1] Sun, W.P. (2003) Musicians Are Prone to Neuromuscular Diseases. Muscle Nerve, 27,549 .

[2] http://medline.org.cn/index.do

[3] Liu, Y.F. and Wang, T.F. (1998) Study and Experiment on the Pathological Mechanism of Chronic Fatigue. Chinese Journal of Basic Medicine in Traditional Chinese Medicine, 4, 157-160.

[4] Li, Z.R. (2003) Experimental Acupuncture Science. China Press of Traditional Chinese Medicine, Beijing, 315.

[5] Ding, X. (2012) Teachers' Prevention of Occupational Diseases. Xinhua Publishing house, 103.

[6] шмидт-шклювская, А. (2002) О профзаболеваниях рук пианиства о воспитании пианистических навыков. издателыства Классика-ХХІ. ленинград, музыка, 134. 